\title{
Rectal Dosage Form
}

National Cancer Institute

\section{Source}

National Cancer Institute. Rectal Dosage Form. NCl Thesaurus. Code C69046.

A substance intended for administration in or around the rectum. 